Revista de la red interuniversitaria de estudios sobre las literaturas rioplatenses contemporáneas en Francia

$23 \mid 2021$

La vereda de enfrente. Cruces entre las literaturas argentina y chilena del siglo $\mathrm{XX}$

\title{
Memorias técnicas de lo vivo en Argentina y Chile
}

Mémoires techniques du vivant en Argentine et Chili

Technical memories of the living in Argentina and Chile

\section{Paula Bertúa}

\section{OpenEdition}

\section{Journals}

Edición electrónica

URL: https://journals.openedition.org/lirico/11847

DOI: $10.4000 /$ lirico. 11847

ISSN: 2262-8339

Editor

Réseau interuniversitaire d'étude des littératures contemporaines du Río de la Plata

Referencia electrónica

Paula Bertúa, «Memorias técnicas de lo vivo en Argentina y Chile», Cuadernos LIRICO [En línea], 23 | 2021, Publicado el 06 enero 2022, consultado el 07 enero 2022. URL: http://journals.openedition.org/ lirico/11847; DOI: https://doi.org/10.4000/lirico.11847

Este documento fue generado automáticamente el 7 enero 2022.

\section{cc)}

Cuadernos LIRICO está distribuido bajo una Licencia Creative Commons Atribución-NoComercialSinDerivar 4.0 Internacional. 


\title{
Memorias técnicas de lo vivo en Argentina y Chile
}

\author{
Mémoires techniques du vivant en Argentine et Chili \\ Technical memories of the living in Argentina and Chile
}

\section{Paula Bertúa}

\section{Tiempos y materias de/en la imagen}

A veces pienso la Memoria como una enredadera que crece y se extiende sobre otras superficies: árboles, paredes, alambrados. De un brazo sale otro y de ése otro más, los rizomas se extienden como dedos, se aferran como colas de mono a la rama. Su raíz ya no se ve, la prueba de su potencia está en el vigor de sus tallos, el volumen de los nudos, la corola de las flores. Hay enredaderas, en Buenos Aires está lleno, que en esta época se tiñen de rojo, un rojo intenso como la marca en el calendario del 24 de marzo. Un rojo dolido por el fin del verano, por el señalamiento perenne -no importa cuántos años pasen- del comienzo de la temporada de sangre. Es una imagen que no dialoga con la rabia fresca que siento cada 24 , pero es la imagen que me sostiene. Soy una hoja más en el muro, con mi testimonio siempre en rojo, con el agua de las voces que lo completaron corriendo dentro de los

tallos que hacen cobijo también a las telas de araña, los bichos palo, las hormigas que laceran y abren espacio para hojas nuevas. Una enredadera 
como un coro indignado que se orquesta según su propio bramido, que no se calla. Crece y crece. Las extremidades más atrevidas se montan sobre el propio follaje y cruzan vacíos en busca de otro muro. Y otro más. La Memoria es movimiento y actualización, un organismo vivo. Marta Dillon, Página 12, 24 de marzo de 2021.

1 Lejos de las consabidas metáforas vegetales que operan como cifra de un crecimiento de tintes bucólicos, la imagen que la escritora y periodista Marta Dillon eligió para recordar el Día Nacional de la Memoria por la Verdad y la Justicia en la Argentina, la memoria como un organismo vivo, adquiere una potencia que la vuelve capaz de socavar una pared, abrirle grietas, impregnarle su humedad hasta quebrarla desde dentro. Este mismo tipo de alegato material es explorado en Aparecida (2015), cruce de crónica, diario íntimo, biografía e investigación documental, donde la escritora relata su encuentro, gracias a un llamado del Equipo de Antropología Forense, con los huesos de su madre, treinta y cinco años después de que la secuestraran y desaparecieran. Son esos huesos que, hechos tierra y resto e "invitados a hablar" desde su más pura materialidad, testimonian lo nunca dicho. Una mirada similar sobre las formas de construcción de la memoria orienta el desarrollo de Cortezas (2014), el breve y conmovedor ensayo donde el filósofo Georges Didi-Huberman traza, mediante un trabajo de montaje de fragmentos, el camino que va desde un deseo de futuro para las generaciones más jóvenes, descendientes de las víctimas del Holocausto, hacia un pasado estallado en pedazos. Mientras contempla algunos fragmentos de cortezas que recogió durante un viaje a Auschwitz-Birkenau, Didi-Huberman se detiene en los restos portadores de memoria que aún subsisten, fotografía lo que ve y reflexiona acerca de la posibilidad de representar el horror.

2 Precisamente el rasgo singular que distingue al siglo XX de su predecesor, que se auspiciaba proyectado hacia el futuro, es la problemática específica relacionada con la pregunta por las condiciones estéticas y las implicancias ético-políticas de la representación de lo inefable, de aquello que desafía los límites de lo que puede ser pensado y dicho. Este tema ha tenido un importante despliegue teórico en relación con los modos de representación de las masacres históricas. En su tratamiento entran en tensión dos posiciones bien conocidas que se han planteado de un modo polarizado: por un lado, la que sostiene la imposibilidad de dar cuenta de lo ominoso a través del arte y que se afirma en la creencia del carácter profundamente disruptivo de ciertas experiencias históricas que dinamitan los marcos interpretativos vigentes, agotan las posibilidades del lenguaje para dar cuenta de la violencia y vuelven moralmente cuestionable y obsceno cualquier intento de representar el exterminio (Adorno 1984; Steiner 2003; Wajcman 2001); por otro lado, lejos de reclamar una clausura para el arte, se erige una voz que expresa la necesidad de creación de poéticas capaces de figurar la violencia política y sus huellas sobre los cuerpos, sobre el imaginario cultural, sobre la sociedad. Poéticas, en suma, capaces de una indagación que permita dar cuenta de aquello que por su violencia parece irrepresentable. Para esta perspectiva, es a través del arte recuperado en su matriz política que el artista emprende su lucha contra el olvido: la escritura, el cine, la fotografía, el arte en tanto desafíos al silencio permiten sobreponerse a lo ominoso y volver palpables las voces, las figuras, las huellas de aquellos aniquilados por la barbarie (Didi-Huberman 2004; Nancy 2006; Cohen 2006). 
3 Ahora bien, entre estas dos posturas se abre un arco de posiciones más interesantes que, por fuera de la polarización, nos permiten pensar el legado del exterminio no en términos de contraposiciones estereotipadas entre lo decible y lo indecible, lo inconmesurable y lo comunicable sino a partir de un desplazamiento desde la aporía de lo irrepresentable al problema de cómo representar el horror. De las aproximaciones figurativas al montaje y el efecto de extrañamiento, del arte de denuncia al abismo de lo representable en lo sublime: múltiples han sido las políticas estéticas que han buscado una salida al atolladero de la representación de lo inefable, de aquello que provoca un estallido de nuestros marcos de inteligibilidad. Entre la posición que sostiene que de la aniquilación nada puede ser representado -o, más bien, que lo que se debe intentar representar es la nada como testimonio de lo imposible- y la que refuta la tesis de lo inimaginable, reclamando la exigencia de dar testimonio, para no caer en el mutismo, en el olvido, y repetir, se abre también una cesura ontológica relacionada con el problema de la representación o, mejor, con la representación como problema. Por un lado, porque el uso inflacionista de la noción de irrepresentable transforma, según Jacques Rancière, "los problemas de regulación de la distancia representativa en problemas de imposibilidad de la representación" (2001: 81). Pero además porque más allá de ciertos interrogantes que jalonan las disputas entre estos enfoques antagónicos (si puede lo irrepresentable mostrarse sin resolver la paradoja que lo constituye o si ese irrepresentable se relaciona con una presencia, con una ausencia o con un real) estos posicionamientos descansan sobre orientaciones y actos interpretativos sobre el ser y la naturaleza específica de las representaciones, entre ellas las visuales, que les otorgan primacía al significado y a la significación, desde una perspectiva preferentemente antrópica.

4 Sin embargo, a la luz del desarrollo del pensamiento posthumano ${ }^{1}$, que se pregunta por la experiencia de lo sensible en relación con diversas entidades existentes, entre ellas el universo objetual del que participan las imágenes técnicas ${ }^{2}$, podríamos ejercitar una vista de paralaje y deslizar, así, el eje de análisis: del significado a la presencia, de la representación a la potencia. Entendida de este modo, la dimensión de lo visual no puede ser del todo trasladada al discurso ni completamente racionalizada. Hay algo en la materialidad -de las obras, de las imágenes, de los artefactos visuales- que excede el significado. En este horizonte de pensamiento, W.T. Mitchell en ¿Qué quieren las imágenes? entiende a los artefactos visuales como "cosas vivas" con una existencia y deriva propias, que poseen atributos como la agencia, la motivación o la autonomía, y que habilitan el acceso a dimensiones emocionales, psíquicas y racionales imbricadas en el estatus ontológico mismo de los objetos.

5 En sintonía con este orden de ideas, la teoría y el arte contemporáneos de las últimas décadas han vuelto una y otra vez sobre el asunto de lo vivo-indagando en las huellas o rastros que las diferentes entidades imprimen en la materia- en relación con planteos inscriptos en el campo de la biopolítica y con las lógicas de existencia orgánica e inorgánica que se expresan en entramados estéticos sensibles. En lo que hace al contexto de las tradiciones culturales latinoamericanas -tensionado por sueños políticos emancipatorios, brutales dictaduras y modernizaciones aceleradas- estas cuestiones delinean un reordenamiento asociado a una desestabilización de la distancia que frecuentemente se estableció entre una naturaleza y una ontología; entre humano y no humano y que, al decir de Gabriel Giorgi, supone la "indagación de una nueva proximidad que es a la vez una zona de interrogación ética y un horizonte de 
politización" (2014:12). En rigor, la pregunta por la relación entre la imagen técnica y lo desaparecido o ausente, su lugar vacante o su espectralidad expresa una imposibilidad de discernir, escandir o delimitar entre lo vivo y lo muerto, lo que no es ni deja de ser, lo que no está ni deja de estar.

En eje con estas problemáticas, me propongo aquí reflexionar en torno de algunas producciones visuales contemporáneas de Argentina y Chile que indagan perturbadoramente en un corpus de restos materiales -orgánicos e inorgánicos- de aquel pasado traumático, procurando advertir los entrecruzamientos con las prácticas del archivo como punto de unión entre una memoria compartida sobre el pasado reciente y las imágenes técnicas que la hacen posible. Asimismo pretendo releer determinados objetos visuales que articulan temporalidades, a partir de la hipótesis de que en dichos retornos se pueden trazar nuevos recorridos históricos y construir nuevos sentidos sobre la vivencia de un pasado colectivo doloroso atravesado por contextos políticos específicos de memoria y justica que, en diferentes períodos, configuraron escenarios desde donde evocar lo vivido ${ }^{3}$. Más allá de tener presente las coyunturas singulares de producción artística que caracterizan las experiencias posdictatoriales chilena y argentina, así como sus disímiles periodizaciones y los modos particulares de tramitación de la memoria en cada caso, propongo aquí un cruce entre las obras de dos artistas contemporáneas con experiencias diversas en relación con la memoria del trauma: la artista visual chilena Celeste Rojas Mugica, hija de un militante del Movimiento de Izquierda Revolucionario (MIR) en Chile y en Ecuador, y la fotógrafa argentina Helen Zout, que vivió las consecuencias directas de la represión, con un intento de secuestro y su consecuente paso a la clandestinidad. A pesar de las diferencias contextuales, vivenciales y generacionales, sus propuestas estéticas convergen en lo que entiendo como el desarrollo de una perspectiva materialista y posthumana de las prácticas memoriales del horror ${ }^{4}$. En los ejercicios de memoria relacionados con lo monumental y con las políticas estatales en torno a los hechos acontecidos durante las dictaduras del Cono Sur, así como en los relatos de la generación contemporánea al trauma, es corriente encontrar en general registros que trabajan sobre el pasado como un contenido más o menos representable, solidario del discurso de la modernidad, que ofrece contenidos cuyo valor de verdad es motivo de disputas políticas, éticas y estéticas (Billi y Lucero 2017). Pero en las últimas décadas, en sintonía con el pensamiento posthumanista, han adquirido protagonismo propuestas estéticas e intelectuales alternativas a esos ejercicios de memoria. En el campo de la fotografía, y en relación con las obras de Rojas Mugica y Zout, se evidencia un uso renovado de los dispositivos técnicos en una apuesta por procesos que no parten de una distribución jerárquica de las formas de existencia y, consecuentemente, no juzgan que la memoria sea una prerrogativa exclusivamente humana.

7 En este sentido, me interesa examinar cómo sus obras visuales participan de una zona particular de la producción artística contemporánea que Florencia Garramuño singulariza por la "actualización de restos materiales en tanto ruina o supervivencia" y por el despliegue de prácticas que "parecen buscar la potencia estética de una imagen del pasado, más que su reconstrucción memorialista" (Garramuño 2016: 2). Porque se diferencian "de toda una línea de la producción estética latinoamericana que en las últimas décadas se vio signada por una política de la memoria y de la reconstrucción del recuerdo" (Garramuño 2016: 3). De este modo, las prácticas fotográficas que examino aquí reactualizan el problema de la relación entre estética y política, y exploran las posibilidades de la imagen técnica para configurar narrativas acordes con 
una experiencia de la temporalidad atravesada por una crisis de la representación, en arreglo a agencias no antrópicas involucradas en las imágenes. Esto implica pensar la construcción del sentido histórico desde cuestionamientos a la historiografía progresiva y también desde lógicas que se descalcen de las dimensiones de la memoria y del testimonio más transitadas, aquellas que enlazan con los modelos referencialistas y con el idealismo significante ${ }^{5}$. Y también entender a la fotografía en relación con temporalidades que exceden el acto y el momento de la toma y de exposición: por un lado, porque el dispositivo apunta al "después de lo humano", que no incumbe tanto a la simple desaparición física y superación conceptual de lo humano, como a la imaginación que sobre esa desaparición en tanto tema visual recurrente se trama en la fotografía. También se relaciona con la apertura a la cuestión de la supervivencia de los artefactos fotográficos e imagéticos como una forma de continuación de los procesos de producción de imágenes en un mundo en el que otras entidades con vida, entre ellas las humanas, habrán desaparecido (Zylinska 2019: 9). Por otro lado, porque hay instancias del antes, donde obran los materiales estéticos -naturales, químicos, culturales- de un espacio común sobre los que la objetualidad fotográfica interviene y modifica un estado de cosas. En este sentido, las imágenes en las que me voy a detener se destacan por articular políticas y poéticas de la memoria bajo la forma de experiencias sobre la historia reciente que conjugan, en un ensamblaje técnico e imaginario, elementos orgánicos e inorgánicos, afectos, trazos y gestos mediante una síntesis novedosa de sus propios materiales.

8 La articulación entre tiempo, materia y memoria habilita varias líneas de abordaje. Por una parte, el problema de la relación entre la duración y el recuerdo está inscripto en el propio dispositivo técnico, en especial en el fotográfico, en tanto el acto de disparar una toma produce un intervalo, un desfasaje temporal que, siguiendo a Henri Bergson, podemos llamar "memoria". Así, el vínculo entre artefacto y pensamiento reposa en la analogía técnica que emparienta el funcionamiento de la memoria con el de la máquina fotográfica (Bergson, 2006). Esa memoria es la duración en un sentido amplio y consiste en hacer fluir el tiempo por fuera de la imagen, ya que es en la espera que el tiempo puede refugiarse mientras se desvanece la imagen y donde surge el durar diferenciado y el devenir de los instantes (Lissovsky 2003). Por otra parte, la imagen derivada de ese proceso conforma una superficie densa donde colisionan materiales de distintas naturalezas, procedencias y temporalidades que actúan en un campo relacional entre diversas entidades y modos de existencia.

\section{Restos y rastros en el territorio}

9 La alusión a la noticia de una imagen misteriosa trazada en el desierto de Atacama fue el disparador de Ejercicios de Aridez, el ensayo crítico y poético que la artista visual Celeste Rojas Mugica (Santiago de Chile, 1987) desarrolló entre 2017 y 2020, mediante una plataforma virtual interactiva, una exposición presencial conformada por videoinstalaciones y fotografías y una publicación impresa ${ }^{6}$. Su estudio de campo se inspiró en un hecho sucedido a fines del 2011, cuando una mujer recibió un sobre anónimo por debajo de la puerta de su casa en un pueblo cercano a San Pedro de Atacama, en la región de Antofagasta. La destinataria de ese mensaje cifrado era la dirigente de una agrupación de ejecutados políticos durante la dictadura de Pinochet; el sobre contenía la imagen satelital de un sable corvo, símbolo de las Fuerzas Armadas 
chilenas, trazado sobre el desierto en grandes dimensiones y a pocos kilómetros de su casa.

Al igual que en otras de sus obras, en Ejercicios de aridez Rojas Mugica apuesta por una reflexión centrada en las marcas que van dejando los materiales sobre los que trabaja en relación con el archivo, con eventos traumáticos del pasado reciente en el Cono Sur y con la construcción de la memoria. En el año 2018 se trasladó hasta el desierto para ver con sus propios ojos aquel geoglifo contemporáneo, signo de la masacre, que alude a un elemento incorporado tempranamente en la historia militar chilena: el sable corvo jugó un papel significativo en la Guerra del Pacífico, momento determinante en la configuración del Estado moderno, pero su uso como instrumento de tortura y exterminio se hizo sistemático durante la dictadura de Pinochet. Se trata de un dibujo de dos kilómetros de extensión, trazado con cal, al igual que otras inscripciones sobre el terreno que lo rodean: un gran círculo de 600 metros y los números 11, 73 y 78, los dos últimos presuntamente alusivos al año del golpe militar e inicio de la operación "Caravana de la Muerte" y al año de la ejecución masiva de la operación "Retiro de televisores", como se le llamó en el ejército al desentierro de prisioneros políticos que habían sido sepultados en fosas clandestinas para arrojarlos a las profundidades del mar, durante el entrenamiento militar desplegado por el Plan Cóndor. La particularidad de estos dibujos es que no pueden percibirse sino a mucha distancia, desde una vista satelital o con un drone. La propuesta visual de Rojas Mugica sobre esas imágenes se desarrolla en una plataforma audiovisual interactiva de su sitio web que procura emular la vista cenital, tanto en los modos de registro de las fotografías del territorio que incorpora la impronta del mapa físico y el mapa político- como en las formas posibles de transitarlo, con una advertencia que desde el inicio reza: "Este sitio es un recorrido".

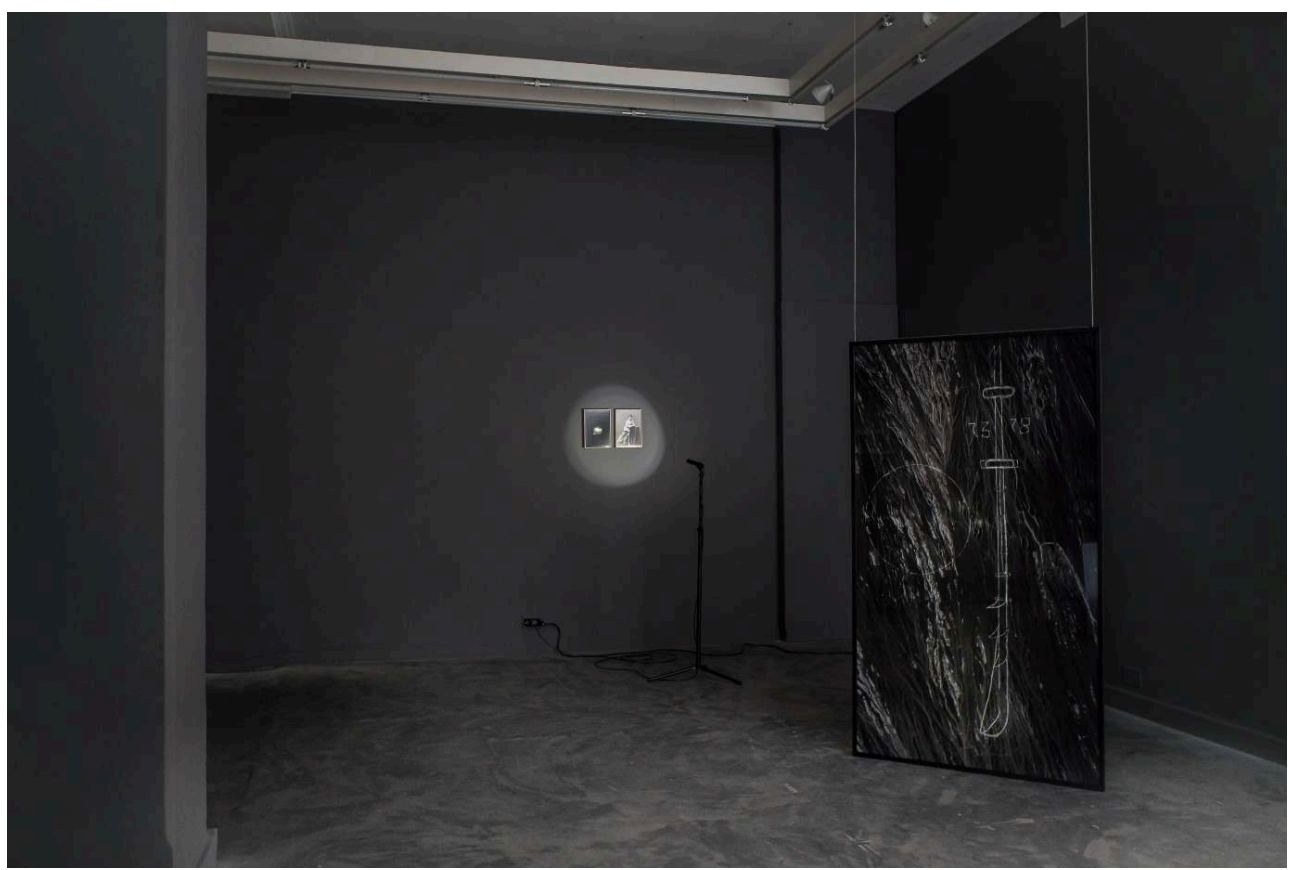

Fig. 1. Celeste Rojas Mugica, de la serie Ejercicios de Aridez (instalación), fotografía a partir de capturas satelitales de archivo. Vista del corvo dibujado en el Desierto de Atacama.

11 Las condiciones físicas del territorio desértico hacen que esa línea de cal se haya mantenido en el tiempo, como una suerte de "tatuaje al cuerpo del país" (Rojas Mugica 
2021), si pensamos el paisaje como un organismo que acusa el impacto de la historia, y sobre el que se imprimen huellas, marcas e intervenciones tanto materiales como simbólicas. En "Aridez hiende", una zona de la instalación que consiste en un video en blanco y negro en loop se recorre esa zona de la superficie de la cordillera, la columna vertebral de la violenta historia reciente, como si se escaneara o radiografiara un cuerpo animal o vegetal por dentro: los surcos del paisaje, mirados en detalle, evocan tendones o bien nervaduras. La instalación conjuga también una serie de fotografías en plano detalle del suelo, sus sustratos minerales, la cal que compone el geoglifo, algunas balas encontradas en el territorio e imágenes de archivo sobre el proceso de exhumación de los cuerpos hallados en la zona, en especial las de unas telas de la vestimenta de un refugiado político, rasgadas por el sable corvo. Ejercicios de aridez juega con una mirada macro y micro, dos tipos de escala que se desmarcan de la perspectiva antrópica para otorgar visibilidad a elementos que yacen en territorios invisibles para la mayoría, debido a su magnitud, su carácter inhóspito y de difícil acceso. Los dispositivos de exhibición que monta Rojas Mugica configuran una arqueología tecno- política de la memoria que aborda de forma compleja el entramado de los espacio-tiempo involucrados. Su propuesta trabaja en la articulación de varios niveles geológicos de materialidad medial: al ras de la superficie del territorio, donde pueden verse las huellas de la historia; en las capas minerales subterráneas, cuya particularidad salobre permitió la conservación de los restos de los asesinados y sepultados en tumbas colectivas; y desde lo que se ve desde el cielo, apuntando a la infinitud del espacio exterior.

De esta forma, Rojas Mugica construye un archivo medial que conecta con la materia y el tiempo profundos de una memoria que es tanto político-cultural como geológica: a la materia bruta de los elementos físicos registrados en territorio, en clave documental, se le sobreimprime la propia materialidad de los dispositivos fotográfico y audiovisual, de factura analógica y digital, un conjunto de máquinas ópticas que fabrican su propia temporalidad sobre una historia tejida entre los tiempos de larga duración del desierto y la "corta historia" del horror dictatorial. Como un bucle retroactivo que apunta al propio dispositivo, se destaca una zona de la instalación compuesta por una serie de pantallas digitales alineadas a la altura de la visión; cada una de ellas aloja la palabra de un poema de Martín Cinzano que se despliega en sentido perimetral en varias líneas: "aridez desaparece en los poros del aire", "mapa físico mapa político", "rasga la carne de la tierra", transpuesto al lenguaje del código morse. Así, la memoria se construye en un punto frágil e intermitente que articula lo más etéreo e intangible ("desaparece", "poros", "aire") con lo más palpable y físico ("carne", "rasga", "tierra"), una zona donde las capas de la Tierra se imbrican con el entramado socio-técnico digital, compuesto, asimismo, por una base fuertemente material de minerales y combustibles fósiles. En Ejercicios de aridez, la artista ensaya una memoria material-medial no humana, en el sentido que Benjamin le atribuía a lo Unmensch, un tipo particular de experiencia donde lo inanimado absorbe todo lo existente como viviente. Y donde constataba los rasgos de una humanidad que se acreditaba en la destrucción, en todo lo que había quedado soslayado en el humanismo clásico por no ser reconocido como humano. Recordemos que en "Experiencia y pobreza" esa deshumanización se relacionaba con el proceso de destrucción que la técnica y la cultura modernas acarreaban. Benjamin proponía entonces una nueva relación con la técnica y con una nueva cultura -la cultura del cristal-, como una salida materialista, imbuida de una utopía política, para sobrevivir a la cultura. Podríamos arriesgar que la propuesta 
estética de Rojas Mugica recoge algo de esa impronta en su imaginación de nuevas formas visuales para la memoria, donde los sustratos técnicos y materiales habilitan nuevas políticas de la vida de lo que aún late o se manifiesta, allí donde lo que se ha desplegado más bien han sido políticas de dominio sobre la vida.

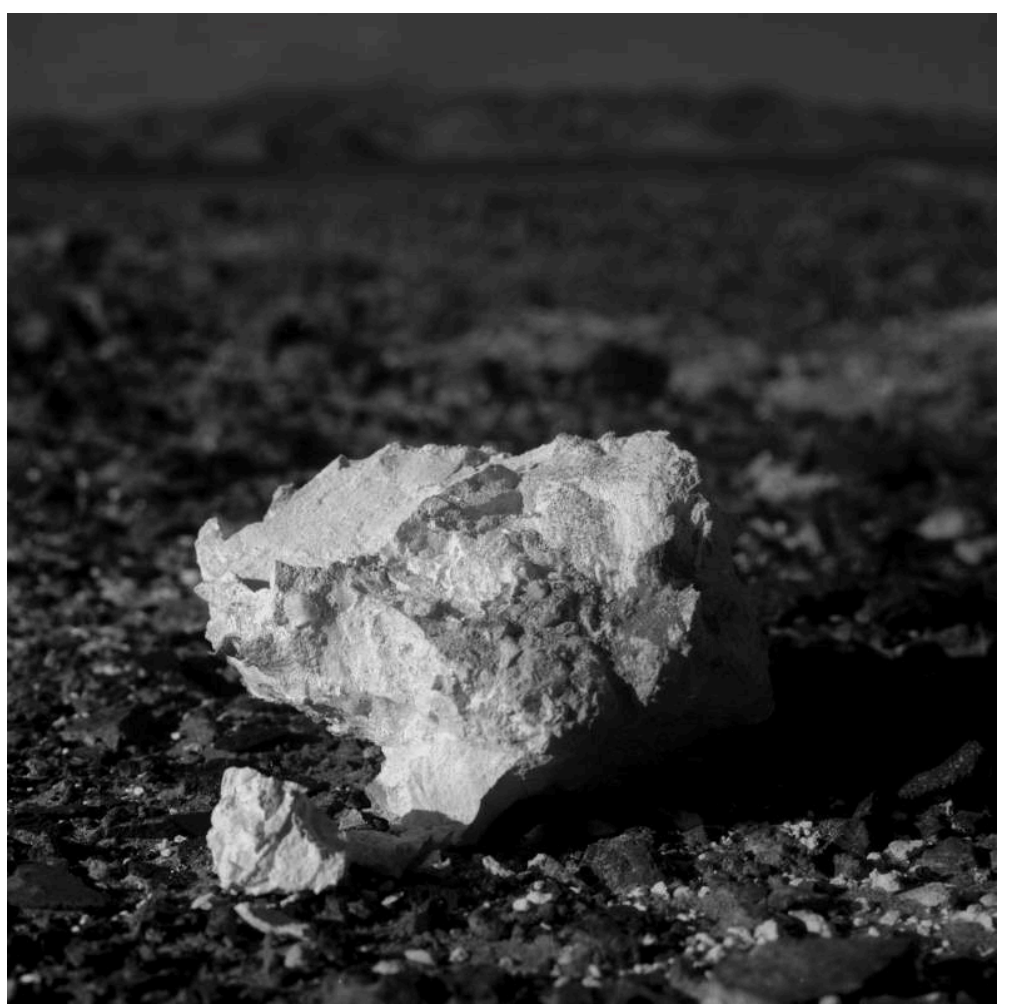

Fig. 2. Celeste Rojas Mugica, de la serie Ejercicios de Aridez, fotografía toma directa B\&N, digital microscópica. Corte transparente de roca en el sitio de ubicación del corvo. 


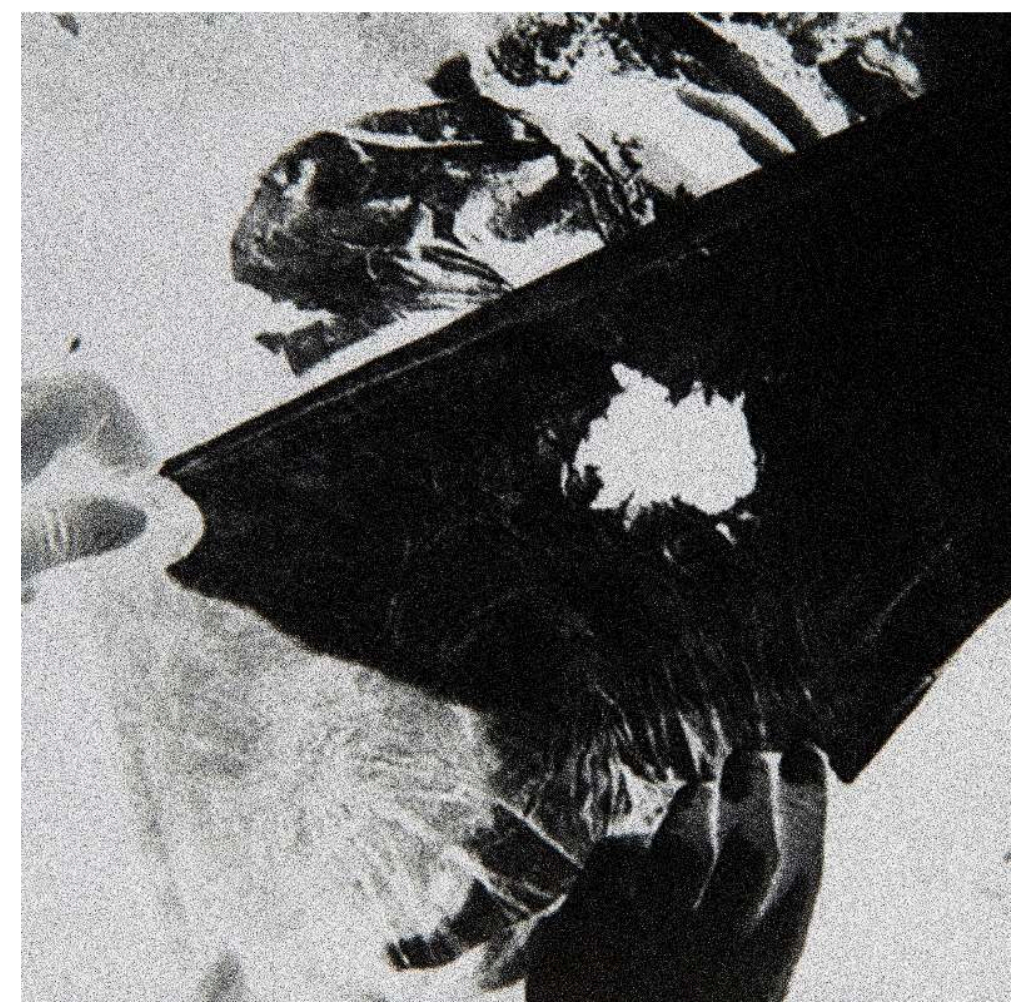

Fig.3. Celeste Rojas Mugica, Exhumación (1), fotografía de archivo. Puñalada de corvo sobre ropa de ejecutado político. Exhumación de cuerpos hallados en el Desierto, víctimas de la Operación "Caravana de la muerte".

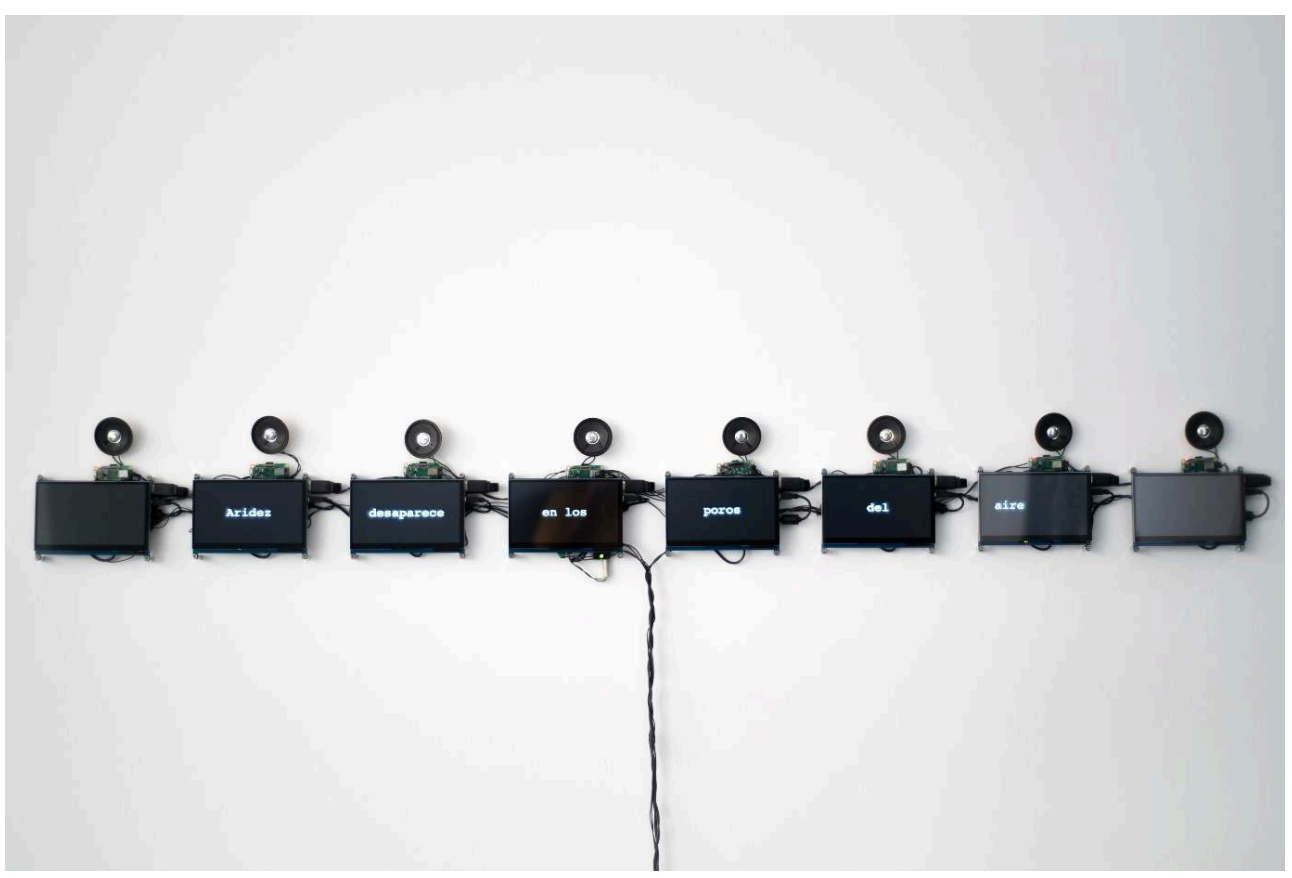

Fig. 4. Celeste Rojas Mugica, Aridez golpea en el lenguaje, Instalación, 8 monitores de 7" y sonido.

Desde hace algunos años ya que la literatura y el arte chilenos de las generaciones que han vivido la experiencia directa de la dictadura, una genealogía que Rojas Mugica recupera y resignifica, han vuelto la mirada hacia el desierto de Atacama, un paisaje ideologizado que remite a la situación precisa del régimen pinochetista, así como también a la zona de explotación privilegiada por el extractivismo neoliberal. En el año 
1993, el poeta Raúl Zurita (Santiago de Chile, 1950) realizaba su intervención más monumental, la famosa inscripción en clave de land art "ni pena ni miedo" en una planicie al sur de Antofagasta, con el objeto de resignificar el territorio en tiempos de posdictadura a partir de una reflexión subjetiva y política ${ }^{7}$. Las letras trazadas en tipografía cursiva, emulando una escritura a mano alzada, imprimían un gesto personal y afectivo sobre el territorio, articulaban poética y visualidad, representación del paisaje y representación nacional, y tensionaban la voluntad de inscripción en el paisaje con las formas en que el entorno respondía a esa inscripción y la reescribía, desde la erosión (Ayala Munita 2021: 104). Pero, como señalamos, la topografía y las condiciones atmosféricas de Atacama lo hacen también un lugar ideal para la conservación de materiales, de restos geológicos, arqueológicos y culturales. En busca de las huellas y rastros indelebles del genocidio, en Nostalgia de la luz (2010) el cineasta Patricio Guzmán (Santiago de Chile, 1941) emprendió un camino de exploración de la geografía material del desierto, que forma una trilogía con sus otros documentales $\mathrm{El}$ botón de nácar (2015), referido al mar y La cordillera de los sueños (2019), a la cordillera de los Andes. Guzmán demuestra que, como un inconmensurable repositorio de capas de sustratos minerales, memorias y tiempos, el desierto conforma un gran archivo vivo que contiene memorias de distinto signo y transcendencia: la de los acontecimientos sucedidos a años luz que los astrónomos estudian para entender la historia del planeta, la de las comunidades originarias que los arqueólogos indagan para leer claves de historias de vida ancestrales, la de los cuerpos de sus desaparecidos que las mujeres de Calama aún buscan denodadamente escarbando en la tierra.

En las propuestas estéticas de estos artistas, en las que participaron equipos transdisciplinarios, la imagen técnica -fotográfica o cinematográfica- interviene sobre diversas entidades del mundo natural y artefactos culturales, como un modo de existencia propio que informa, en el sentido de dar forma, y transduce ${ }^{8}$ aspectos de lo vivo a conjuntos materiales externos (Rodríguez en Simondon 2007: 20) que, a su vez, no son aprehensibles por fuera de las condiciones de posibilidad que esos dispositivos habilitan La materia orgánica sobre la que opera la ingeniería técnica de esas imágenes podría considerarse "como un todo indiviso... un fluir más que una cosa" (Bergson 1994:10) que posee su propia vitalidad e historicidad. En torno de esa materia deviniente, energética y plástica opera la técnica que da forma, que en sí misma también posee su propia ontogénesis, pues es un modo de ser y no una simple derivación de un real. En tanto materia, esas imágenes establecen relaciones reales -y no solo imaginarias- con otras entidades del mundo. Las obras de Rojas Mugica, Zurita y Guzmán actúan, pues, como "cristales de tiempo" en sentido deleuziano, enhebrando el presente y el pasado en una misma coexistencia, en ese "punto de indiscernibilidad" (Deleuze 2014: 98) que conforma una fusión entre lo real y lo imaginario, lo presente y lo pasado, lo actual y lo virtual en esa argamasa que entendemos por memoria.

\section{Proyecciones orgánicas, objetos y huesos}

Desde el año 1999 y durante el lapso de diez años la fotógrafa Helen Zout (Santa Fe, 1957) realizó una investigación visual sobre los rastros de desapariciones de la última dictadura militar en la Argentina, con el objetivo de, siguiendo sus palabras, "recomponer un cuerpo ausente (que es el de los desaparecidos) a través de las huellas dejadas en los presentes y en los lugares donde ocurrieron los hechos, que para mí 
guardan la memoria de la desaparición" (Zout 2006a) . Mediante un trabajo paciente y sostenido, Zout llevó a cabo la exhumación de materiales de archivos judiciales, policiales y de inteligencia donde persigue las secuelas que la represión dejó tanto en los sobrevivientes y en los familiares de desaparecidos como en los centros clandestinos de detención, un conjunto de marcas que configuran lo que concibe como una "memoria corporizada" (Zout 2006b) y situada del horror.

Restos óseos alojados en la morgue judicial, operaciones de reconocimiento de territorios donde funcionaron áreas de detención, el interior de un avión utilizado en los llamados "vuelos de la muerte", un predio con fosas comunes, la costa del Río de la Plata, las manchas de sangre y la firma en un expediente judicial: en Desapariciones, nombre que da título a esta ecléctica serie, la fotógrafa arma su propio parlamento de los escenarios y las cosas, un diagrama de materialidades portadoras de memoria que registran el paso del tiempo y sus accidentes, y que fundan un orden propio de derecho. El acto de fotografíar a esas entidades sienta jurisprudencia, les otorga derecho a existir, a ser visibilizadas. Varios tipos de existencia son registrados por la imagen fotográfica desde una "ética de la literalidad" (Moreno 2006), de donde emerge una verdad más radical que la meramente fáctica. En primer lugar, las piezas de cadáveres, como el cráneo que Zout fotografía en plano detalle, en tanto presencia tangible de lo muerto, ponen en tensión el reparto de lo vivo y lo no vivo mediante un retorno obsceno del cuerpo no velado. El cadáver interroga la gestión de las formas de vida e instala el problema por el gobierno de los cuerpos, los territorios y las materias que impone el estado de excepción. En segundo lugar, esos espacios, habitados por fuerzas, eventos y afectos llevan la atención de la mirada hacia las inscripciones, agenciamientos y emergencias de la materia que traman un "decir material" (Cóccaro 2021: 92), presencias que desfondan un determinado concepto de vida a partir de un "detalle mínimo con un máximo de potencia inquietante" (Moreno 2006). Al respecto, la reflexión sobre la serie hecha por la escritora María Moreno enfatiza cierto giro performático de los materiales a favor de una expresividad mineral:

¿Puede un río ser culpable de encubrimiento y asociación para el delito de genocidio? El antropomorfismo agita las aguas de las marinas de Turner hasta que la imagen, en su turbulencia, se animiza como alma atormentada. Pero la fotografía que Helen Zout tomó de un rincón de la costa en Punta Lara, en el lugar donde las corrientes arrojaron el cuerpo de un desaparecido, es aún más inquietante (2006). 


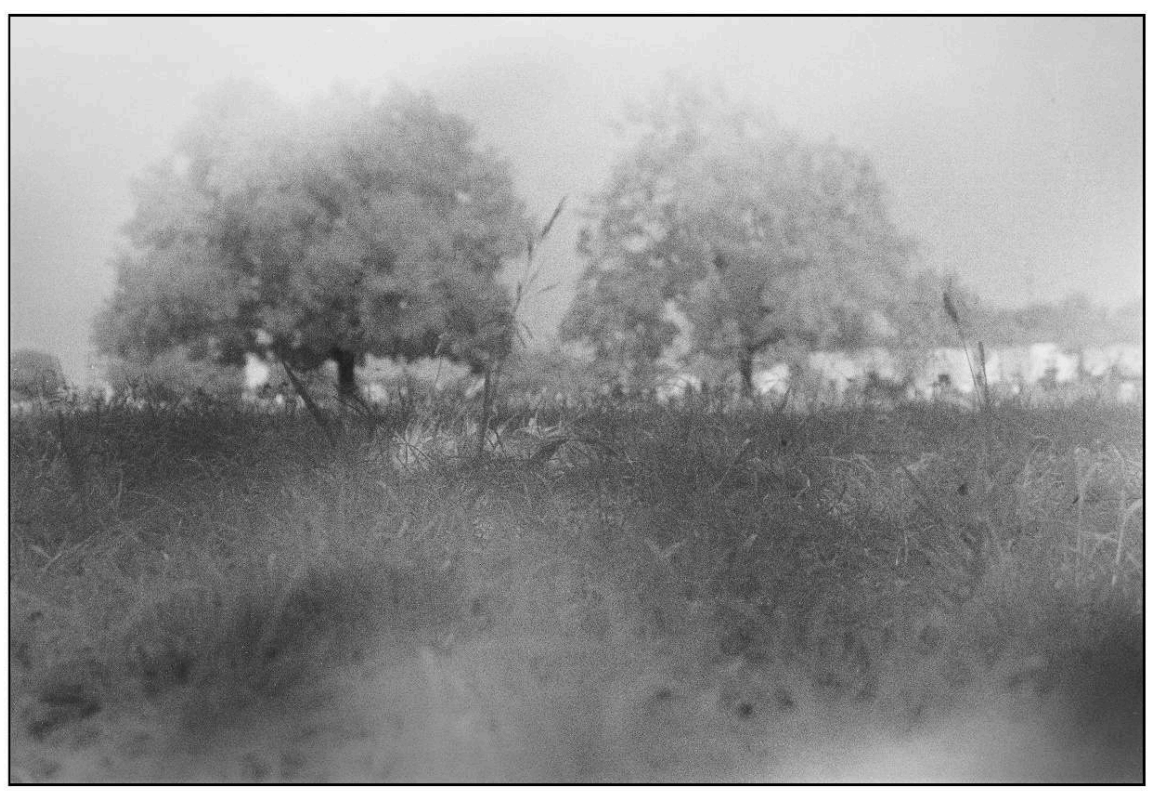

Fig. 5. Helen Zout, Predio con fosas comunes en el cementerio de Quilmes, provincia de Buenos Aires.

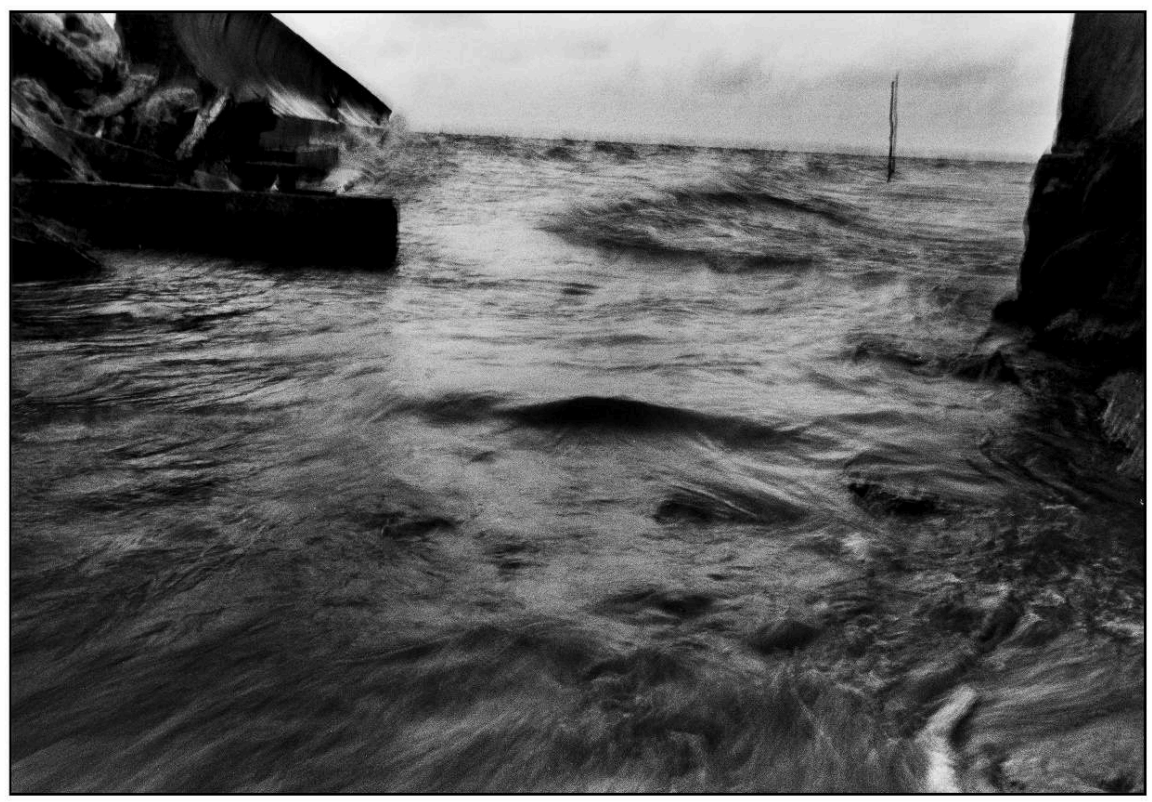

Fig. 6. Helen Zout, Lugar donde fue encontrado un cuerpo no identificado en 1976, Punta Lara, Río de la Plata.

De la serie de Zout, hay dos fotografías que hacen eje en lo que podríamos llamar una "memoria del paisaje", un recordatorio situado que revisita los escenarios naturales del horror: la foto del predio con las fosas comunes en el cementerio de Quilmes y la de la costa del Río de la Plata, en Punta Lara, donde fue encontrado un cuerpo no identificado en 1976. Allí se anuda la memoria de los cuerpos desaparecidos con la memoria de la tierra y del agua, el fondo terrestre y cristalino cuya materia reivindica una nueva relación estética y ética con el entorno. Si decimos que en las fotos de Zout se perfila una memoria del paisaje esta no se reduce a la mera construcción de una 
mirada que lo abarca ni al resultado material que el humano deja al culturizarlo, sino que emerge como un ensamble humano - no humano. Esas fotos movidas, fuera de foco, fueron tomadas en una especie de estado de trance, la misma figura que Jens Anderman encuentra en la obra poética de Juan L. Ortiz y que se corresponde con una "suspensión del juicio", una disposición de los humanos a participar, de un modo más ético y natural del entorno: "trance de la tierra que emerge en esta experiencia humillante y que nos devuelve del mundo-objeto sometido a la visión soberana del sujeto, el suelo interobjetual de 'materialidades vibrantes' que abren paso a una exología política tendiente a "transformar la división entre sujetos hablantes y objetos mudos"” (Anderman 2018: 26).

Desapariciones forja una visualidad compleja que pone el acento en la objetualidad pura. Porque frente a la fotografía científica, judicial y forense -desplegada en las mismas escenas y que convivía con sus tomas- Zout opone la fotografía como una práctica no reductible a esos discursos (y su legalidad) sobre la memoria del pasado reciente, pero que también contrarresta la proliferación de actos, puestas en escena y exposiciones que, en cada recordatorio del Día Nacional de la Memoria por la Verdad y la Justicia, saturan el espacio representacional con la pretensión de suturar un vacío. Zout perturba el paradigma representativo, en principio, a partir de una deliberada política del desenfoque, la veladura y el fuera de foco que vuelve dificultosos el reconocimiento y la interpretación de lo que es dado a ver. Sus fotografías arman una serie, mezcla de destello y fragmentación, así como opera la memoria. Por el movimiento y los claroscuros, sus tomas nos recuerdan las famosas fotografías tomadas desde dentro de la cámara de gas en Auschwitz y que inspiraron el ensayo de Georges Didi Huberman Imágenes pese a todo. Sabemos, sin embargo, que las fotografías de Zout no fueron tomadas en situaciones extremas, que no pueden reproducir "eso que ha sido" pero hacen "como si" (incluso algunas dan la sensación de haber sido robadas al momento). Precisamente ese "como si" es el que las vuelve tan inquietantes y perturbadoras.

Zout evita cualquier consumación de la mirada que decante en un subjetivismo. Probablemente una de las operaciones más elocuentes de la serie sea la desplegada en la fotografía de Jorge Julio López, no solo por lo que la imagen refiere, simboliza y anticipa ${ }^{10}$. A las estrategias más consabidas de representación de la experiencia concentracionaria, que pretenden colmar la ausencia con distintas formas de reposición, figuración o imaginación de lo ocurrido, la fotógrafa opone un recorte y una sustracción. Una fotografía, de tipo carnet, deja ver el rostro y los hombros desnudos de López que, con los ojos cerrados y sus párpados apretados, niega el reconocimiento que todo retrato habilita a través de la mirada, desestabiliza las convenciones representativas de la figura humana. Mediante esta imagen no vemos el horror, sino el escamoteo de los ojos que lo vieron. Son ojos que han visto mucho, son ojos que han visto demasiado. Pero esa mirada, aunque ha presenciado el horror en primera persona, no repone su percepción para nosotros. Años más tarde, el fotógrafo cordobés Gabriel Orge (Belle Ville, 1967) en su serie Apareciendo (2014-2015) ${ }^{11}$ haría proliferar esa fotografía ya emblemática de López, replicándola como intervenciones en entornos urbanos y naturales, sobre edificios, ríos y árboles. El cuerpo de López, dos veces desaparecido, emergía del paisaje, fusionado a diversas superficies, agujereando e interrumpiendo la experiencia de un presente con la pregunta que su presentificación actualiza ¿Dónde está Julio López?, que es tanto una interrogación por su paradero como un reclamo por su aparición con vida. 


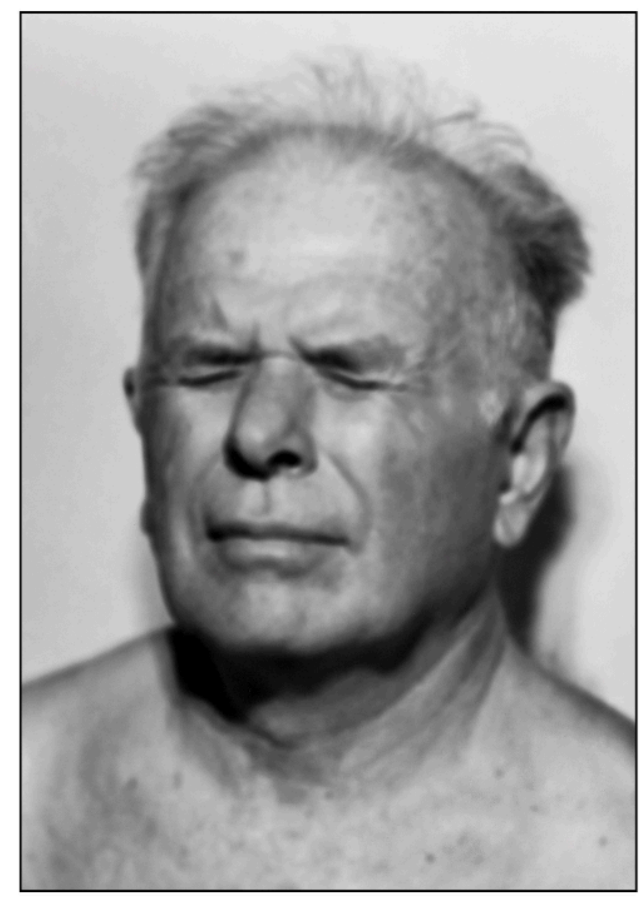

Fig. 7. Jorge Julio López, sobreviviente del centro clandestino Arana, La Plata, 2000.

\section{Conclusiones}

En su conocido ensayo La insubordinación de los signos, la crítica Nelly Richard reflexiona, a partir de la experiencia chilena, sobre la memoria de las últimas dictaduras cívicomilitares, la exploración de las temporalidades inconclusas abiertas por el trauma y las estrategias estéticas insurgentes que tramaron prácticas impugnadoras de la cultura del autoritarismo. La figura de la memoria, nos dice, ha sido una de las más convocadas en tanto mantiene una tensión irresuelta entre "recuerdo y olvido, latencia y muerte, revelación y ocultamiento, prueba y denegación, sustracción y restitución" a partir de la narración del cuerpo nacional y la imagen de sus restos sin hallar ni sepultar (2000:13). El modo en que Richard despliega, desde una perspectiva explícitamente deudora de la dialéctica benjaminiana, toda una serie de problemas relacionados con la historia residual del trauma -las estrategias de lo refractario, la delación fotográfica, las discontinuidades temporales y la estética del deshecho- deja el terreno preparado para la búsqueda de otras fibras de la materialidad, tal como hemos intentado desarrollar aquí, indagando en el espesor de objetos estéticos específicos y sus materiales -mitad físico-mitad mentales- cargados de potencialidades, animados de fuerzas y dinamismos internos que hacen de ellos una realidad con vida propia. Las propuestas estéticas de Celeste Rojas Mugica y de Helen Zout que hemos recorrido en este ensayo se inscriben, a su modo, en los debates abiertos en torno de las políticas y las formas imaginarias de la memoria reciente sobre los procesos dictatoriales latinoamericanos que han hallado en las artes audiovisuales un espacio de formulación y problematización novedoso. Si bien las dimensiones del testimonio y el documento representan las claves más conspicuas de la mayoría de las propuestas artísticas, hemos demostrado cómo también existen producciones, como las de las artistas estudiadas, que plantean una apertura 
exploratoria hacia otras construcciones de la memoria que se expanden hacia formas de lo inorgánico, más allá de lo viviente.

¿Qué clase de existencia tienen esas imágenes fotográficas capaces de mostrar sin congelar, como habitualmente tienden a hacer las poéticas restitutivas de lo inefable? Podríamos pensarlas como existencias en el límite de la no-existencia, esas que Étienne Souriau denominaba realidades virtuales, y que David Lapuojade rebautiza como existencias menores, no en virtud de su insignificancia sino por la fragilidad, evanescencia y espectralidad que las caracteriza y que las dota de una particular intensidad, de una potencia de indeterminación donde la vida (sustraída) se afirma en su carácter inacabado (Lapoujade 2018). Por los materiales que las constituyen e informan, las producciones visuales contemporáneas en las que nos detuvimos se abren a una dimensión de conexiones, transformaciones y metamorfosis inesperadas que resultan de la vida de esas sustancias orgánicas e inorgánicas en un mundo anterior o posterior al humano, pre y post humano al mismo tiempo. Es sobre ese continuum de la existencia fotográfica como un milieu, es decir, un medio de vida (Rancière 2008), que la memoria encuentra cauces de expresión despegados de cualquier intencionalidad cumplida en una conciencia dadora de sentido.

Las imágenes de las artistas que consideré en este ensayo demuestran cómo la fotografía, portadora de una ontología propia, puede estimular y animar una vida que la excede, allí donde la sustracción, la muerte y el silencio parecieran sellar una clausura. Porque esas imágenes -donde convergen fuerzas naturales, sociales y políticas- redimensionan el tiempo profundo de la memoria técnica de la historia. Lo redimensionan desde una suerte de grado cero de la experiencia estética que extraña la percepción, en un mundo surgido del interior de sus perspectivas. Los formalistas rusos lo advirtieron tempranamente cuando, frente a la idea de un arte como mero reconocimiento, proponían el extrañamiento como motor de cambio que desautomatizara la percepción. Uno de sus representantes más brillantes y heterodoxos, Viktor Shklovski, leía en Jolstomer, el famoso relato de Tolstoi narrado desde la voz de un caballo, un procedimiento de los más poderosos para mostrarnos el mundo como si lo viéramos por primera vez. Probablemente haya algo en el orden de esa forma de revelación de lo sensible que atraviesa estas imágenes sobre la memoria reciente, imágenes donde la sustancia fotográfica performa en el cuerpo a cuerpo de sus materiales.

\section{BIBLIOGRAFÍA}

Andermann, Jens, Tierras en trance. Arte y naturaleza después del paisaje, Santiago, Metales pesados, 2018.

Adorno, Theodor, Crítica cultural y sociedad, Madrid, Sarpe, 1984. Traducción de Manuel Sacristán.

Ayala Munita, Matías, "Ni pena ni miedo”, de Raúl Zurita: desierto y erosión”, Estudios de Teoría Literaria. Revista digital: artes, letras y humanidades, $n^{\circ} 21$, vol.10, marzo 2021, Facultad de 
Humanidades, Universidad Nacional de Mar del Plata, p. 103-116. Web. Consultado el 15 de abril de 2021.

Bergson, Henri, La evolución creadora, Barcelona, Planeta, 1994. Traducción de M. L. Pérez Torres.

---, Materia y memoria, Buenos Aires, Cactus, 2006. Traducción de Pablo Ires.

Bertúa, "Escrituras de la sombra: la fotografía como gesto", HeLix, Dossiers zur romanischen Literaturwissenschaf, Universidad de Heidelberg, $n^{\circ} 14,2020$, p. 88-106. Web. Consultado el 20 de abril de 2021.

Billi, Noelia y Guadalupe Lucero, "Cuerpos de memoria vegetal. Una perspectiva materialista y posthumana de los ejercicios memoriales del horror", ponencia presentada en I Jornadas Internacionales "Cuerpo y violencia en la literatura y las artes viusuales contemporáneas", Facultad de Filosofía y Letras, Universidad de Buenos Aires, 2017. Mimeo.

Blejmar, Jordana, Natalia Fortuny y Luis Ignacio García (eds.), Instantáneas de la memoria. Fotografía y dictadura en Argentina y América Latina, Buenos Aires, Libraria, 2013.

Braidotti, Rosi, Lo posthumano, Barcelona, Gedisa, 2015. Traducción de Juan Carlos Gentile Vitale. Brodsky, Marcelo y Julio Pantoja (ed.), Body Politics/ Políticas del Cuerpo en la Fotografía Latinoamericana, Buenos Aires, La Marca Editora, 2009.

Cóccaro, Victoria, “La imaginación fósil en Aranha, de Nuno Ramos: del viviente muerto al fósil parlante", Estudios de Teoría Literaria. Revista digital: artes, letras y humanidades, $\mathrm{n}^{\circ}$ 21, vol.10, marzo 2021, Facultad de Humanidades, Universidad Nacional de Mar del Plata, p.91-102. Web. Consultado el 15 de abril de 2021.

Cohen, Esther, Los narradores de Auschwitz, México, Fineo/ Lilmod, 2006.

Deleuze, Gilles, La imagen-tiempo. Estudios sobre cine 2, Paidós Comunicación, 2014. Traducción de Irene Agoff.

Didi- Huberman, Georges, Imágenes pese a todo. Memoria visual del Holocausto, Paidós, Barcelona, 2004.Traducción de Mariana Miracle.

---, Cortezas, Satander-Cantabria, Shangrila, 2014. Traducción de Mariel Manrique y Hernán Maturet.

Dillon, Marta, Aparecida, Buenos Aires, Editorial La Página, 2018.

---, “Un organismo vivo”, Página 12, 24 de marzo de 2021, Web. Consultado el 25/04/2021.

Fortuny, Natalia, Memorias fotográficas. Imagen y dictadura en la fotografía argentina contemporánea, Buenos Aires, La Luminosa, 2014.

Garramuño, Florencia, “Sobrevivencias y fantasmas contemporáneos. Otras formas de la memoria", ponencia presentada en coloquio La constitución dinámica de la memoria cultural: prácticas estéticas y (re)mediatizaciones (1950-2015). UNAM, Facultad de Filosofía y Letras, 2 de mayo de 2016. Mimeo

Giorgi, Gabriel, Formas comunes. Animalidad, cultura, biopolítica, Buenos Aires, Eterna Cadencia, 2104.

Goffard, Nathalie, Imagen criolla. Prácticas fotográficas en las artes visuales de Chile, Santiago de Chile, Metales Pesados, 2013.

Harman, Graham, Hacia el realismo especulativo, Buenos Aires, Caja Negra, 2015. Traducción de Claudio Iglesias. 
Lapoujade, David, Las existencias menores, Buenos Aires, Cactus, 2018. Traducción de Pablo Ires. Latour, Bruno, Reensamblar lo social. Una introducción a la teoría del actor-red, Buenos Aires, Manantial, 2005. Traducción de Gabriel Zadunaisky.

Lissovsky, Mauricio, “A maquina de esperar”, Gondar, Jô y Miguel Ángel Barrenechea (org.), Memória e Espaço: trilhas do contemporáneo, Rio de Janeiro, 7 Letras, 2003, p. 15-23.

Longoni, Ana y Gustavo Bruzzone (comps.), El Siluetazo, Buenos Aires, Adriana Hidalgo, 2008.

Longoni Ana Luis Ignacio García, “Imágenes invisibles: acerca de las fotos de desaparecidos”, Blejmar, Jordana, Natalia Fortuny y Luis Ignacio García (eds.), Instantáneas de la memoria. Fotografía y dictadura en América Latina, Buenos Aires, Libraria, 2013, p.25-44.

Meiselas, Susan (ed.), Chile from Within, 1973-1988, Nueva York/Londres, W.W. Norton Company, 1991.

Mitchell, W.J.T, ¿Qué quieren las imágenes? , Buenos Aires, Sans Soleil, 2017. Traducción de Isabel Mellén.

Moreno, María, “Sombras”, Página 12, Suplemento Radar, 19 de marzo 2006. Web. Consultado el $20 / 04 / 2021$.

Nancy, Jean-Luc, La representación prohibida, Barcelona, Amorrortu, 2006. Traducción de Margarita Martinez.

$\mathrm{N}$ de R, “Mensaje escrito en el desierto”, La Estrella, Valparaíso, 8 de octubre de 1993, p. 7.

Oyarzún, Pablo, “Parpadeo y piedad”, Cirugía plástica, NGBK, 1989, p. 29-39

Rancière, Jacques, “S'il y a de l'irreprésentable”, Le Genre humain n 36, 2001.

--- “Ce que 'medium' peut vouloir dire: l'exemple de la photographie”, Jean-Louis Déotte et al., Le milieu des appareils, Paris, L'Harmattan, collection "Esthétiques", 2008, p. 23-36.

Richard, Nelly, La insubordinación de los signos, Santiago de Chile, Cuarto Propio, 2000.

Rodriguez, Pablo, "El modo de existencia de una filosofía nueva", Gilbert Simondon, El modo de existencia de los objetos técnicos, Buenos Aires, Prometeo, 2007, p. 9-24. Traducción de Margarita Martínez y Pablo Rodríguez.

Simondon, Gilbert, El modo de existencia de los objetos técnicos, Buenos Aires, Prometeo, 2007. Traducción de Margarita Martínez y Pablo Rodríguez.

Steiner, George, Lenguaje y silencio. Ensayos sobre la literatura, el lenguaje y lo inhumano, Barcelona, Gedisa, 2003. Traducción de Miguel Ultorio, Tomás Fernández Aúz y Beatriz Eguibar.

Wajcman, Gérard, El objeto del siglo, Buenos Aires, Amorrortu, 2002. Traducción de Irene Agoff.

Zout, Helen, Desapariciones, Colección Fotógrafos Argentinos, Buenos Aires, Dilan Editores, 2009.

--- "Las huellas que la dictadura dejó en López" (entrevista de la redacción), Página 12, 15 de octubre 2006a. Web. Consultado el 13/03/2021.

---, "La memoria corporizada", Página 12, 15 de octubre 2006b. Web. Consultado el 13/03/2021.

---, Huellas de desapariciones, Buenos Aires, Centro Cultural de la Memoria Haroldo Conti, 2015.

Zylinska, Johana, A fotografía depois do humano, Copenhague/ Río de Janeiro, Zazie Edições, 2019. 


\section{NOTAS}

1. Sigo en la definición de este concepto a Rosi Braidotti, quien considera la condición posthumana contemporánea como un aspecto crucial de nuestra historicidad, una inflexión a nuestro modo de pensar las características que definen lo común de nuestra especie, nuestra política y la relación con el planeta. Braidotti postula una subjetividad posthumana que rebate la distinción categórica entre la naturaleza y la cultura, desnaturalizando las diferencias sociales para demostrar su contingencia. Y se interroga por el tipo de análisis político sostenido por la aproximación basada en el continuum naturaleza-cultura, aspecto que considera central en la agenda de la situación posthumana. Véase Braidotti (2015).

2. En el terreno de la estética es posible problematizar la agencia no-humana, si pensamos las obras a la luz, por ejemplo, del modelo de objetualidad derivado del paradigma del realismo especulativo. Las obras en tanto que objetos portadores de agencia, participan en redes mediadas por efectos y significados (Latour 2005). Si la premisa fundamental es una crítica a la idea de excepcionalidad y separación de lo humano de toda otra modalidad de existencia, las capacidades de agencia se encuentran distribuidas entre todos los entes existentes. En esta línea se inscribe la propuesta de Graham Harman, de una ontología orientada a objetos (000), basada en un solo tipo de entidad, los objetos, y en la premisa de que todo objeto se sustrae a sus relaciones, que también son objetos (2015).

3. Por los límites del alcance del objeto de este artículo, no me detengo aquí en la producción fotográfica contemporánea a las dictaduras argentina y chilena, un corpus voluminoso integrado por: las imágenes de la acción artística conocida como el Siluetazo, registrada por el fotógrafo Eduardo Gil, las fotografías de prensa de la época o publicadas por los medios en las noticias sobre operativos policiales, muchas de las cuales fueron reunidas en el libro-collage de León Ferrari, Nosotros no sabíamos, 1976 (2008), para el contexto argentino, o la fotografía de artistas del campo cultural chileno que documentaron el proceso dictatorial (Paz Errázuriz, Alejandro y Álvaro Hoppe, Helen Hugges, Jorge Ianiszewski, Héctor López, Kena Lorenzini, J.D. Marinello, Christian y Marcelo Montecino, Oscar Navarro, Claudio Pérez, Luis Poirot, Paulo Schlavevsky, Luis Weinstein y Oscar Whittke, entre otros), así como también los debates sobre la cuestión fotográfica que se producían en el Chile dictatorial entre fotógrafos y críticos (Eugenio Dittborn, Ronald Kay, Enrique Lihn y Adriana Valdés). Sobre estos temas, véanse, entre otros: Longoni y Bruzzone (2008), Longoni y García, (2013), Bertúa (2020), Richard (2000), Oyarzún (1989) y Meiselas (1991).

4. En este artículo tomo como antecedente inspirador el abordaje de la colectiva Materia de esta perspectiva, en especial, el trabajo de Noelia Bili y Guadalupe Lucero sobre el despliegue de una "memoria vegetal" como potencia imaginaria en los relatos vinculados a la memoria de los campos de concentración y exterminio del terrorismo de Estado en Argentina. Véase Billi y Lucero (2017).

5. Con esta línea se filia un importante cuerpo de estudios sobre las memorias fotográficas acerca del pasado reciente en Argentina y América Latina, que constituye un área de problematización central y que tomo como antecedentes (véanse Blejmar et al. 2013; Goffard 2013; Fortuny 2014, entre otros). Me interesa, sin embargo, ensayar aquí otro tipo de acercamiento en torno a la objetualidad y agencialidad fotográficas en relación con la memoria, el tiempo y la materialidad desde modos expresivos que producen estructuras imaginarias y formales más allá del paradigma hermenéutico o comunicacional de interpretación.

6. La plataforma virtual interactiva puede recorrerse en el sitio web de la artista: https:// ejerciciosdearidez.com/ ; una exposición del estudio de campo, con curaduría de Florencia Battiti, se llevó a cabo en la galería ROLF, entre el 26 de marzo y el 28 de mayo de 2021: https:// rolfart.com.ar/exhibition/ejercicios-de-aridez/ 
7. La frase "ni pena ni miedo", que se corresponde con las últimas palabras del libro La vida nueva (1994), de Raúl Zurita, fue escrita con material desértico en letras de 250 metros de alto y 40 de ancho. En su realización intervinieron ingenieros, geólogos y geógrafos que removieron 53 mil metros cúbicos de material con retroexcavadoras, buldozers y motoniveladoras. Su costo fue de 40 millones de pesos chilenos, obtenidos con la venta de obra de artistas chilenos, aportes de particulares y de funcionarios de Obras Públicas. En N de R. "Mensaje escrito en el desierto", La Estrella, Valparaíso, 8 de octubre de 1993, p. 7.

8. Entiendo la noción de transducción tal como Gilbert Simondon la ha definido: una "individuación en progreso", un tipo de relación que es tanto de transmisión como de traducción y que involucra el paso de un registro a otro -entre los mundos físico, psíquico, vivo, colectivo y artificial- donde lo transportado es asimismo transformado. Véase Simondon (2007).

9. La serie Desapariciones puede verse en el sitio web de la artista: http://www.helenzout.com.ar/. Fue expuesta en numerosos espacios de exhibición y publicada en volúmenes individuales y colectivos: Véanse: Zout (2009 y 2015), y Brodsky y Pantoja (2009).

10. Jorge Julio López fue un sobreviviente del centro clandestino de detención Arana de La Plata, retratado por Helen Zout en 2000. Su testimonio fue clave en los Juicios por la Verdad abiertos en 1998, donde declaró como víctima y testigo en el juicio por delitos de lesa humanidad en el que fue condenado a prisión perpetua el represor Miguel Etchecolatz. Poco después de declarar y un día antes de que se dictara la sentencia condenatoria, el 18 de septiembre de 2006, fue desaparecido.

11. En el sitio web http://www.boladenieve.org.ar/artista/189/orge-gabriel se puede acceder a algunas piezas de la serie.

\section{RESÚMENES}

En el contexto de las tradiciones culturales latinoamericanas -tensionado por sueños políticos emancipatorios, brutales dictaduras y modernizaciones aceleradas-ciertas producciones visuales contemporáneas de Argentina y Chile revisitan aquellos sueños y pesadillas, procurando advertir sus entrecruzamientos con la fina materia de lo vivo, con las prácticas del archivo como punto de unión entre una memoria compartida sobre el pasado reciente y las imágenes técnicas que la hacen posible. Propongo analizar esos objetos visuales, que conjugan, en un ensamblaje técnico e imaginario, elementos orgánicos e inorgánicos, afectos, trazos y gestos mediante una síntesis novedosa de sus propios materiales, y que articulan temporalidades alternativas para construir nuevos recorridos históricos y formas de memoria sobre el pasado.

Dans le contexte des traditions culturelles de l'Amérique Latine -mises à l'épreuve par des rêves politiques émancipateurs, des dictatures brutales et des modernisations accélérées- certaines productions visuelles contemporaines d'Argentine et du Chili revisitent ces rêves et ces cauchemars, en essayant de remarquer leurs intersections avec la subtile matière du vivant, avec les pratiques de l'archive comme point d'union entre une mémoire partagée sur le passé récent et les images techniques qui la rendent possible. Nous proposons d'analyser ces objets visuels, qui combinent, dans un assemblage technique et imaginaire, des éléments organiques et inorganiques, des affects, des traces et des gestes moyennant une nouvelle synthèse de leurs propres matériaux, où on peut trouver une articulation des temporalités alternatives pour construire de nouveaux parcours historiques et formes de mémoire sur le passé. 
In the context of Latin American cultural traditions -tensioned by emancipatory political dreams, brutal dictatorships and accelerated modernizations- certain contemporary visual productions from Argentina and Chile revisit those dreams and nightmares, trying to notice their intersections with the fine matter of the living, with the practices of the archive as a point of union between a shared memory about the recent past and the technical images that make it possible. I propose to analyze these visual objects, which combine, in a technical and imaginary assembly, organic and inorganic elements, affects, imprints and gestures through a new synthesis of their own materials articulating alternative temporalities building new historical paths and forms of memory on the past.

\section{ÍNDICE}

Keywords: Memory, Technique, Recent Past, Argentina, Chile.

Mots-clés: memoire, techniques, passé recent, Argentina, Chile

Palabras claves: memoria, técnica, pasado reciente, Argentina, Chile

\section{AUTOR}

\section{PAULA BERTÚA}

CONICET-UNTREF/UBA

paula.bertua@gmail.com 